\title{
Screening of anticonvulsant effect of carvedilol on electrically induced convulsions in Wistar albino rats
}

\author{
Biacin Babu $^{1 *}$, Madhavrao Chavan ${ }^{2}$
}

\author{
${ }^{1}$ Department of Pharmacology, Malabar Medical College Hospital and Research Centre, Calicut, Kerala, India \\ ${ }^{2}$ Department of Pharmacology, All India Institute of Medical Sciences, Mangalagiri, Andhra Pradesh, India
}

Received: 26 October 2020

Accepted: 13 November 2020

\author{
*Correspondence: \\ Dr. Biacin Babu, \\ Email: drbiacin84@gmail.com
}

Copyright: (C) the author(s), publisher and licensee Medip Academy. This is an open-access article distributed under the terms of the Creative Commons Attribution Non-Commercial License, which permits unrestricted non-commercial use, distribution, and reproduction in any medium, provided the original work is properly cited.

\begin{abstract}
Background: Epilepsy is one of the major central nervous system disorders. The parent study aimed to screen the anticonvulsant effect of carvedilol on electrically induced convulsions in Wistar albino rats.

Methods: This study was done in Wistar albino rats. A total of 30 rats were divided into 6 groups each of six rats. group-I (0.9\% normal saline), group-II diphenylhydantoin $(10 \mathrm{mg} / \mathrm{kg} / \mathrm{BW} / \mathrm{ip})$, group-III carvedilol (1mg/kg/BW/PO), group-IV carvedilol ( $2 \mathrm{mg} / \mathrm{kg} / \mathrm{BW} / \mathrm{PO})$ and group-V carvedilol $(4 \mathrm{mg} / \mathrm{kg} / \mathrm{BW} / \mathrm{PO})$. All the groups were administered drugs and subjected to electric shock. Scores of seizures and percentage of protection were recorded to compare between the groups. One was ANOVA (post hoc) followed by Dunnet t test applied to find the statistically significant between the groups.

Results: Group-I showed significant difference compared to other groups. Group-II showed significant difference with group-III and IV not with V. High dose of test drug and standard drug showed similar results in percentage of seizures prevention. Control and low doses of test drugs showed significant difference compared to standard and high dose of test drug in seizures prevention.

Conclusions: High of carvedilol showed significant seizures prevention compared to low doses and control group.
\end{abstract}

Keywords: Albino rats, Carvedilol, Convulsions, Diphenylhydantoin, Epilepsy, Maximal electroshock seizure

\section{INTRODUCTION}

Epilepsy is a chronic disorder of the central nervous system characterized by recurrent seizures associated with disturbance of consciousness and/or a characteristic body movement (convulsions) and sometimes autonomic hyperactivity. ${ }^{1}$ The characteristic event in epilepsy is a seizure which is a paradoxical event due to abnormal, unpredictable, excessive, periodic, hyper synchronous discharges from an aggregate of central nervous system neurons. The word seizure is derived from Latin word sacire, which means "to take possession of". Seizures are said to be "non-epileptic" when the normal brain is evoked by electroshock or chemical agents induced convulsions, or "epileptic" when occurring without evident provocation. ${ }^{2}$ Seizures that are the result of an acute reversible systemic or neurological condition like metabolic disturbance or central nervous system (CNS) infections are not considered to be epilepsy as they usually abate once the underlying condition has resolved. Similarly, febrile seizures are not considered as epilepsy. ${ }^{3}$ Currently various drugs are used to treat epilepsy. But they are all associated with some limitations. Development of new drugs has always remained an important need. Recently, a new generation of antiepileptic drugs has reached the market. In early clinical trials, these agents have shown the promise of increased efficacy with decreased toxicity relative to the older generation of antiepileptic drugs, but it is clear that they are neither magic bullets nor panaceas for epilepsy. Even though the exact pathophysiology has not been well understood, there is still a battle to find better efficacious and tolerated drugs 
and many of which are in the pipeline. According to literature, beta blockers also have some role in the protection of seizures. The present study aimed to study the anticonvulsant effect of carvedilol on electrically induced convulsions in Wistar albino rats.

\section{METHODS}

\section{Study settings and period}

This study was done in Department of Pharmacology, Sree Mookambika Institute of Medical Sciences, Kulasekharam, Tamil Nadu. The study protocol was approved by Institutional animal ethics committee (IAEC).

\section{Animals}

Wistar albino male rats weighing 150-250 g were obtained from the central animal house, Sree Mookambika Institute of Medical Sciences. Total 30 rats were used in the study. All the animals used for the experiment were maintained on standard laboratory food pellets and water ad libitum. The animals were transferred to the experimental room of central animal house for a period of 5-6 hours/day for acclimatization. ${ }^{3}$ rats were placed in a single plastic perspex cage at room temperature $(27 \pm 20 \mathrm{C})$, humidity 70 $80 \%$, maintaining $12 \pm 1$ hour light and dark cycle. ${ }^{4}$ The experimental animals were fasted for 8 hours prior to the study with free access only to water. All the experiments were performed in the experiment lab of the central animal house at the same time of the day (between 9:00 AM and 1:00 PM) to minimize influences of circadian rhythm on seizure susceptibility.

\section{Groups}

Group-I: Normal saline $(0.9 \% / 10 \mathrm{ml} / \mathrm{kg} /$ orally $)$.

Group-II: Diphenylhydantoin (10 mg/kg/BW/ip).

Group-III: Carvedilol (1 mg/kg/BW/PO).

Group-IV: Carvedilol (2 mg/kg/BW/PO).

Group-V: Carvedilol (4 mg/kg/BW/PO).

\section{Maximal electroshock seizure}

The test drug carvedilol was administered orally in doses of 1,2 and $4 \mathrm{mg} / \mathrm{kg}$ body weight to groups III, IV and V respectively. The standard drug diphenylhydantoin (10 $\mathrm{mg} / \mathrm{kg}$ body weight intraperitoneally) was administered to the rats in group II. Thirty minutes after administration of the above drugs the animals were induced seizures using electro-convulsiometer with corneal electrodes. The eyes of animals were moistened with normal saline and local anaesthetic ( $2 \%$ lignocaine) before applying corneal electrodes. The intensity of stimulus used was $150 \mathrm{~mA}$ of current at frequency of $60 \mathrm{~Hz}$ for duration of 0.2 seconds.
Presence or absence of tonic hind limb extension (THLE) was noted. ${ }^{5}$ The seizures were also scored as follows:

\section{Scores description 6}

0: No seizure.

1: Forelimb extension without hind limb extension.

2: Complete forelimb extension with partial hind limb extension.

\section{3: Complete THLE.}

4: Post ictal depression.

\section{Statistical analysis}

The data was expressed in mean and standard deviation. Statistical package for social sciences (SPSS) 16.0 version used for analysis. One-way ANOVA (post hoc) followed by Dunnet $t$ test applied to find the statistically significant between the groups. $p$ value less than $0.05 \quad(\mathrm{p}<0.05)$ considered statically significant at $95 \%$ confidence interval (CI).

\section{RESULTS}

The study observed scores of seizures and percentage of protection of tonic hind limb extension and compared between the groups.

Table 1: Comparison of scores of seizures and percentage of protection of tonic hid limb extension between the groups.

\begin{tabular}{|c|c|c|}
\hline Groups & $\begin{array}{l}\text { Scores of } \\
\text { seizures } \\
(\text { mean } \pm \text { SD })\end{array}$ & $\begin{array}{l}\text { Percentage of } \\
\text { protection of tonic } \\
\text { hid limb extension } \\
(\%)(\text { mean } \pm \text { SD })\end{array}$ \\
\hline Group-I & $4.00 \pm 0.00$ & $00.00 \pm 0.00$ \\
\hline Group-II & $0.50 \pm 0.00 *$ & $100.00 \pm 0.00 *$ \\
\hline Group-III & $3.00 \pm 0.00^{\#}$ & $33.33 \pm 0.45^{* \#}$ \\
\hline Group-IV & $9.00 \pm 0.00 * \# \$$ & $66.67 \pm 0.94 * \# \$$ \\
\hline Group-V & $0.50 \pm 0.00 * \$ 1$ & $100.00 \pm 0.00 * \$ \|$ \\
\hline \multicolumn{3}{|c|}{$\begin{array}{l}* \mathrm{p}<0.05 \text { significant compared group-I with other groups, } \\
\# \mathrm{p}<0.05 \text { significant compared group-II with other groups, } \\
\$ \mathrm{p}<0.05 \text { significant compared group-III with other groups, } \\
\| \mathrm{p}<0.05 \text { significant compared group-IV with other groups }\end{array}$} \\
\hline
\end{tabular}

\section{Assessment of scores of seizures in maximal electroshock seizure model}

The study showed statistically significant decrease in scores of seizures in group-II $(\mathrm{p}<0.01)$, group-IV $(\mathrm{p}<0.05)$ and group-V $(\mathrm{p}<0.01)$ when compared to group-I. There was also decrease in scores of seizures in group- $\mathrm{V}$ when compared to group-III, but it was not found statistically significant $(\mathrm{p}>0.05)$. There was also decrease in scores of seizures in group-III when compared to group-I, however 
it was not found statistically significant $(p>0.05)$. No statistically significant difference was found between group-II when compared to group-III, group-IV and group$\mathrm{V}(\mathrm{p}>0.05)$ (Table 1 and Figure 1).

\section{Assessment of the percentage of protection of THLE in maximal electroshock seizure model}

In this study all of the animals in group-I had THLE, however, none of the animals in group-II exhibited tonic hind limb extension. The percentage of protection of tonic hind limb extension in group-III, group-IV and group-V was $33.33 \%, 66.67 \%$ and $100 \%$ respectively (Table 1 and Figure 2).

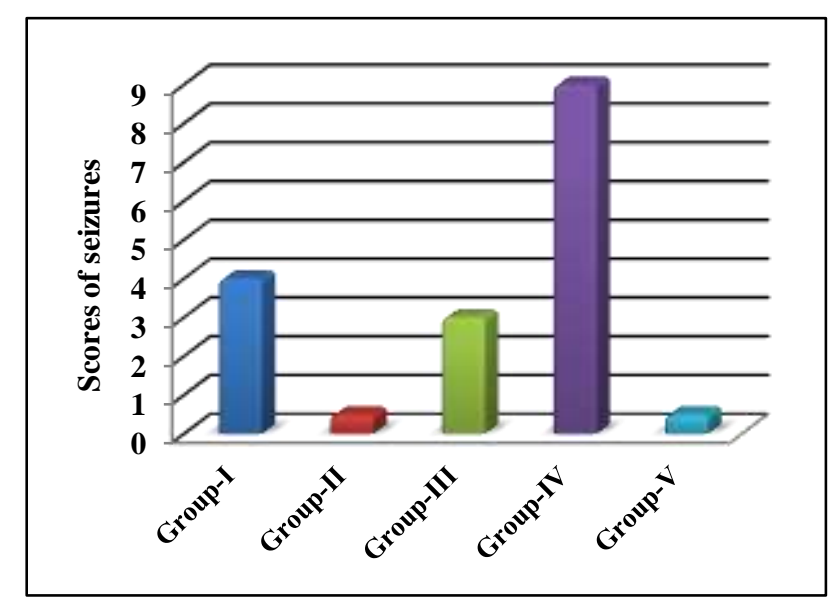

Figure 1: Comparison of scores of seizures between the groups.

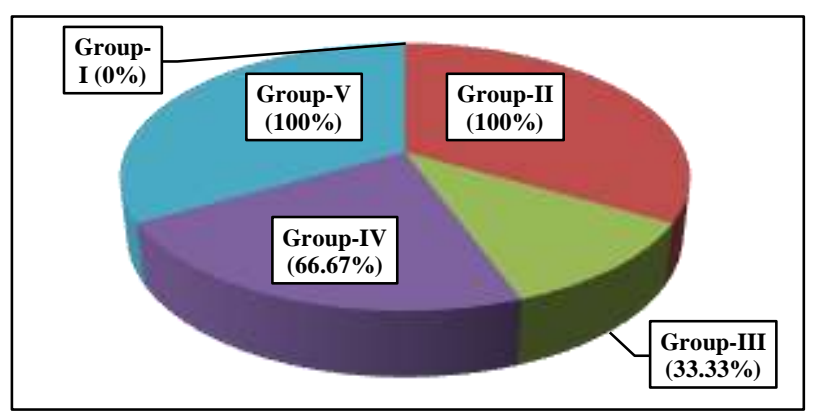

Figure 2: Comparison of percentage of protection of tonic hid limb extension between the groups.

\section{DISCUSSION}

There was also a significant decline in scores of seizures in maximal electroshock seizure model in both carvedilol treated animals (2 mg/kg BW and $4 \mathrm{mg} / \mathrm{kg} \mathrm{BW}$ ) and phenytoin treated animals in comparison with the control group. The decline in scores of seizures in carvedilol groups was dose dependent with highest decline in carvedilol $4 \mathrm{mg} / \mathrm{kg} \mathrm{BW}$ and least decline in carvedilol (1 $\mathrm{mg} / \mathrm{kg} / \mathrm{BW})$. The decline in scores of seizures in dose dependent manner in maximal electroshock seizure model in carvedilol (1 mg/kg/BW, $2 \mathrm{mg} / \mathrm{kg} / \mathrm{BW}$ and $4 \mathrm{mg} / \mathrm{kg} /$
BW) was comparable to standard drug diphenylhydantoin group. Carvedilol has good lipid solubility and hence crosses the blood brain barrier effectively. ${ }^{7-11}$ Adequate concentration of carvedilol in the brain can be one of the factors to control seizures. In a study done by Louis et al it was shown that the centrally present beta-adrenoceptors when blocked by non-selective beta-blockers both propranolol and timolol (in low doses) produced anticonvulsant action, but practolol, a selective beta-1 antagonist, did not show any anticonvulsant action. This indicated that the anticonvulsant action of propranolol and timolol was due to the blockade of beta- 2 receptors. It was also demonstrated that local anaesthetics have a protective effect against convulsions induced by maximal electroshock seizure model. The membrane stabilization action of propranolol in high doses $(>1 \mathrm{mg} / \mathrm{kg} \mathrm{BW}$ in rats) was postulated to be the likely mechanism of action in PTZ induced convulsions in rats. ${ }^{12}$ Carvedilol has a membrane stabilizing action may be due to the inactivation of sodium channels and likely the mechanism of its anticonvulsant action. Studies by Kajiwara et al showed that carvedilol caused a reduction in catecholamine secretion by a suppressive effect on voltage dependent $\mathrm{Na}^{+}$channel, nicotinic acetylcholine ion channel (activated by carbachol) and voltage gated $\mathrm{Ca}^{2+}$ channel. ${ }^{13}$

Carvedilol stimulated translational and post translational steps involved in $\mathrm{Na}^{+}$channel synthesis and inhibited internalization of $\mathrm{Na}^{+}$channels. This was mainly by up regulating vesicular trafficking in the Golgi apparatus. But no change was observed in the pharmacology of $\mathrm{Na}^{+}$ channels on prolonged exposure to carvedilol. Instead carvedilol accumulated in the plasma membrane and may produce a long-lasting persistent blockade of $\mathrm{Na}^{+}$channels. Excess flow of $\mathrm{Ca}^{2+}$ inside the neuronal cell causes depolarization of cell resulting in initiation of seizures. ${ }^{14,15}$ This calcium inflow is due to activation of L-type calcium channels found in the cerebral cortex. ${ }^{16}$ Beta- 1 adrenoceptors when stimulated activate adenyl cyclase which in turn increases cAMP levels that activate the down-stream events like opening of L-type $\mathrm{Ca}^{2+}$ channels. Carvedilol has $\mathrm{Ca}^{2+}$ channel blocking properties by direct action on $\mathrm{Ca}^{2+}$ channels (in high doses) or indirectly by blocking beta-1 receptors and preventing downstream events. Thus, the blockade of L-type $\mathrm{Ca}^{2+}$ channels by carvedilol can be one of the mechanisms of its antiseizure action. The results of our study are consistent with the study results of previous studies reported in literature. From this present study it has been found that carvedilol has anticonvulsant activity in maximal electroshock seizure induced models in Wistar albino rats which suggest that this drug may be effective in grand mal and petit mal epilepsies.

\section{CONCLUSION}

Carvedilol showed significant anticonvulsant effect which is similar to standard drug. In order to understand the exact basis of anticonvulsant activity of carvedilol further studies are required in in-vitro and in-vivo models. Clinical 
efficacy of carvedilol in epilepsy needs to be confirmed from further clinical studies in humans.

Funding: No funding sources

Conflict of interest: None declared

Ethical approval: The study was approved by the Institutional Ethics Committee

\section{REFERENCES}

1. Lowenstein DH. Seizures and epilepsy. In: Fauci AS, Braunwald E, Kasper DL, Hauser SL, LongoDL, Jameson JL et al editors. Harrison's principles of internal medicine vol II. 17th edition. New York:McGraw-Hill. 2008:2498-2512.

2. McNamara JO. Pharmacotherapy of the epilepsies. In: Laurence LB, John SL, Keith LP editors. Goodman and Gilman's Pharmacological Basis of Therapeutics. 12th edition. New Delhi: McGraw-Hill. 2011;583607.

3. Tripathi KD. Essentials of medical pharmacology. 7th edition. New Delhi: Jaypee brothersmedical publishers. 2013;512-38.

4. Vogel HG. Drug discovery and evaluation: Pharmacological assays. 3rd edition. Berlin: Springer. 2008: 662-709.

5. Jalapure SS, Salahuddin M, Imtiyaz SM, Manvi FV. Anticonvulsant effects of Calotropis procera root in rats. Pharmaceutical Biology. 2009;47(2):162-7.

6. Medhi B, Prakash A. Practical Manual of Experimental and Clinical Pharmacology. 1st edition. Jaypee brothers. 2010: 186-204.

7. Thomas CW, David PW. Adrenergic Agonists and Antagonists. In: Laurence LB, John SL, Keith LP editors. Goodman and Gilman's Pharmacological Basis of Therapeutics. 12th edition. New Delhi: McGraw-Hill. 2011:292-333.

8. Hudson SA, McAnaw J, Dreischulte T. Chronic heart failure. In: Walker R. Whittlesea $\mathrm{C}$ editors. Clinical
Pharmacy and Therapeutics. 5th edition. London: Elsevier. 2012;333-53.

9. Shaughnessy KMO. Adrenergic mechanisms and drugs. In: Bennett PN, Brown MJ, Sharma P editors. Clinical Pharmacology. 11th edition. London: Elsevier. 2012;382-427.

10. Liu S. Adrenergic agents. In: Beagle JM, Block JH. Wilson and Gisvold's Organic Medicinal and pharmaceutical chemistry. 12th ed. New Delhi: Lippincott Williams and Wilkins. 2011;519-54.

11. Gupta SK. Drug screening methods. 2nd edition. Jaypee brothers. 2009;400-22.

12. Louis J, Papanicaulao J, Summers RJ. Role of central adrenoceptors in control of PTZ induced seizures in rats. Br J Pharmac. 1982;75:441-6.

13. Kajiwara K, Yanagita T, Nakashima Y, Wada A. Differential effects of short and rolonged exposure to carvedilol on voltage dependant $\mathrm{Na}+$ channels in cultured bovine adrenal medullary cells. J Pharmacol Exp Ther. 2002;302:211-8.

14. Frantseva MV, Velazquez PJL, Tsoraklidis G, Mendonca AJ, Adamchik Y, Burnham MW et al. Oxidative stress is involved in seizure-induced neurodegeneration in the kindling model of epilepsy. Neurosci. 2000;97:431-5.

15. Medhi B, Prakash A. Practical Manual of Experimental and Clinical Pharmacology. 1st edition. Jaypee brothers; 2010:186-204.

16. Walker MC, Surges R, Fisher A. Mechanism of antiepileptic drug action. In: Simon S, Emilio P, Engel JJ editors. The treatment of epilepsy. 3rd edition. Singapore: Wiley Blackwell; 2009:94-95.

Cite this article as: Babu B, Chavan M. Screening of anticonvulsant effect of carvedilol on electrically induced convulsions in Wistar albino rats. Int $\mathbf{J}$ Basic Clin Pharmacol 2020;9:1803-6. 